\title{
MicroRNA-300 decreases cell viability, inhibits migration and promotes apoptosis of osteosarcoma cells via downregulation of Twist1
}

\author{
JINPENG JIA ${ }^{1}$, PEI YIN ${ }^{2}$, GANG HAN ${ }^{1}$, MENG XU $^{1}$, WEI WANG ${ }^{1}$ and WENZHI BI ${ }^{1}$ \\ ${ }^{1}$ Department of Orthopaedics, General Hospital of Chinese People's Liberation Army, Beijing 100853; \\ ${ }^{2}$ Department of Nephrology, First Affiliated Hospital of PLA General Hospital, Beijing 100037, P R. China
}

Received September 2, 2016; Accepted June 8, 2017

DOI: $10.3892 / \mathrm{mmr} .2017 .7023$

\begin{abstract}
Osteosarcoma (OS) is the most frequently occurring pediatric bone malignancy in the world. Numerous miRNAs have previously been demonstrated to participate in the initiation and development of OS. The present study aimed to reveal the role of microRNA-300 (miR-300) in OS cells and elucidate the underlying mechanism involved. The expression of miR-300 in the MG63 human OS cell line was monitored via quantitative polymerase chain reaction (qPCR). Following transfection with miR-300 mimic, miR-300 inhibitor or scramble control, MG63 cell viability, migration and apoptosis were respectively measured by 3-(4,5-dimethyl-2-thiazolyl)-2,5-diphenyltetrazolium bromide (MTT), modified two-chamber migration assay and flow cytometry. Dual-Luciferase reporter assays, qPCR and western blot analysis were subsequently performed to verify whether Twist 1 was a direct target of miR-300. Furthermore, the expression levels of nuclear factor (NF)- $\mathrm{kB}$ pathway proteins were detected via western blot analysis. In MG63 cells, miR-300 was effectively overexpressed or suppressed by transfection with miR-300 mimic or inhibitor, respectively $(\mathrm{P}<0.001)$. Overexpression of miR-300 significantly suppressed cell viability and migration, whereas it enhanced apoptotic rate $(\mathrm{P}<0.001)$. miR-300 suppression exhibited contrary results $(\mathrm{P}<0.05, \mathrm{P}<0.01$ or $\mathrm{P}<0.001)$. Twist1 was demonstrated to act as a direct target of miR-300, and was negatively regulated by miR-300. In addition, miR-300 overexpression downregulated the expression of the primary factors involved in the NF- $\mathrm{BB}$ signaling pathway. These effects on OS
\end{abstract}

Correspondence to: Dr Wenzhi Bi, Department of Orthopaedics, General Hospital of Chinese People's Liberation Army, 28 Fuxing Road, Beijing 100853, P.R. China

E-mail: biwenzhi873@126.com

Dr Pei Yin, Department of Nephrology, First Affiliated Hospital of PLA General Hospital, 51 Fucheng Road, Beijing 100037, P.R. China E-mail: yinpei223@126.com

Key words: osteosarcoma, microRNA-300, Twist1, NF-кB signaling pathway cell proliferation and apoptosis may be due to the miR-300 targeting of Twist1 and the suppressive effect on the $\mathrm{NF}-\kappa \mathrm{B}$ signaling pathway.

\section{Introduction}

Osteosarcoma (OS) is a highly malignant and metastatic disease, characterized by developing rapidly and difficulty in treatment, these characteristics result in its association with high mortality in children and adolescents (1). Currently, tumor resection operation, chemical therapy and radiation therapy are mainly treatments for OS. However, the high degree of limb pain after surgery and resistance to radiation therapy are still difficult to overcome (2). Previous studies about OS have focused on the immune gene, tumor suppressor gene, antisense gene, suicide gene, gene combined and gene vectors in gene therapy of this disease (3). Nevertheless, a better understanding of the molecular mechanisms in OS is still needed and will be helpful in diagnosing and treating this disease.

MicroRNAs (miRNAs) are endogenous small molecule single-stranded RNAs (about 22-25 nucleotides long), known to play important posttranscriptional regulatory roles in plants and animals (4). MiRNAs are involved in the complex life process, including organism growth and development, organ formation, cell proliferation and cell apoptosis. Moreover, it is quite remarkable that a single miRNA can regulate the expression of key proteins which involved in different signaling pathways and different processes in cell physiology (5). MiRNA expression and functions that are associated with the etiology of diseases were first reported in the case of Fragile X syndrome (6). Thereafter, several studies proposed that the abnormal expression of miRNAs was closely related with tumor development and metastasis, and miRNAs were expected to be a breakthrough in the treatment of cancer (7). An increasing number of studies have reported that multiple miRNAs served as tumor suppressors and key regulators in cancers (8). However, the known of miRNAs target genes and its role in various tumorigenesis stages were still limited. Previous studies have confirmed that abnormal expression of miR-300 was related with cancer cell proliferation and apoptosis, and a previous study in MG63 
cell line indicated the pro-proliferation and pro-invasion roles of miR-300, but the exactly role of miRNA-300 in OS has not been exhaustively investigated to our knowledge (9).

The main objective of the present study was to investigate the effect of miR-300 in OS cells and the associated mechanism. In the present study, miR-300 mimic, mimic control, miR-300 inhibitor, or inhibitor control were transfected into MG63 cells (a human OS cells line), respectively. The effect of miR-300 on MG63 cells viability, migration and apoptosis were investigated in vitro. Furthermore, the transcription factor Twist1 has been confirmed as a target gene of miR-106b, miR-720 and miR-33b (10), and the correlations between Twist1 and miRNAs have been proved to be involved in cancer cells modulations (11). Therefore, we also assessed Twist 1 as the target of miR-300 in MG63 cells and the protein level changes of main factors in NF- $\mathrm{KB}$ signaling pathway to detect the possible molecular mechanisms of miR-300 in OS. The present study might provide supplementing certification for basic understanding of miR-300 in OS and possibilities of it usage in OS treatment.

\section{Materials and methods}

Cell culture and transfection. Human OS cell line MG63 were obtained from the American Type Culture Collection (Rockville, MD, USA), and cultured in Dulbecco's modified Eagle's medium (DMEM; Gibco, Grand Island, NY, USA) containing $10 \%$ heat-inactivated feral bovine serum (FBS; HyClone, Logan, UT, USA), $100 \mathrm{U} / \mathrm{ml}$ penicillin and $100 \mathrm{U} / \mathrm{ml}$ streptomycin (Gibco) in the incubator at $37^{\circ} \mathrm{C}$ with $5 \% \mathrm{CO}_{2}(12)$.

MG63 cells were transfected with miR-300 mimic, miR-300 inhibitor, or their scramble controls (Shanghai GenePharma Co., Ltd., Shanghai, China), respectively. Twist1 coding sequence was amplified by PCR and cloned into pcDNA $^{\text {TM }} 3.1$ vector (Thermo Fisher Scientific, Inc., Beijing, China) to construct pcDNA3-Twist1, then the recombinant vector and empty vector as control were transfected into MG63 cells, respectively. The transfection was performed by using Lipofectamine 3000 (Invitrogen Life Technologies, Carlsbad, CA, USA) according to the manufacturer's instructions. After $48 \mathrm{~h}$ of transfection, cells were collected for the further analysis.

Cell viability assay. After transfection, cell viability was assessed using the 3-(4,5-dimethylthiazol-2-yl)-2,5-diphenyltetrazolium bromide (MTT) colorimetric assay according to the standard methods. In brief, cells were seeded into 96-well plates at a density of $2 \times 10^{3}$ cells/well. After 1-4 days of incubation, $20 \mu \mathrm{l}$ of MTT (Sigma, St. Louis, MO, USA) was added into each well and incubated for another $4 \mathrm{~h}$ at $37^{\circ} \mathrm{C}$. Then, $150 \mu \mathrm{l}$ dimethylsulfoxide (DMSO; Sigma) was added and the plates were shaken for $10 \mathrm{~min}$. Each experiment was performed 3 times. Absorbance was measured at $570 \mathrm{~nm}\left(\mathrm{OD}_{570}\right)$ with a 680 microplate enzym-linked immunosorbent assay (ELISA) reader (Bio-Rad Laboratories, Inc., Hemel Hempstead, UK).

Cell migration assay. Cell migration was determined by using a modified two-chamber with $8.0 \mu \mathrm{m}$ pore membranes (Greiner 662638). The transfected MG63 cells were suspended in $200 \mu \mathrm{l}$ of serum-free culture medium, and were added in the uper compartment of 24-well transwell culture chamber. Then $600 \mu \mathrm{l}$ complete culture medium was added to the lower comparment, cells were incubated at $37^{\circ} \mathrm{C}$ for $12 \mathrm{~h}$. After that, cells were fixed with $4 \%$ methanol (NIST, USA) for $30 \mathrm{mim}$, non-transferred cells were removed from the upper surface of the filter carefully with a cotton swab. Traversed cells in the lower were stained with $0.1 \%$ crystal violet for $20 \mathrm{~min}$ and counted under an optical microscope (Leica Microsystems GmbH, Wetzlar, Germany).

Cell apoptosis assay. Flow cytomety analysis was performed to identify and quantify the apoptotic cells by using Annexin V-FITC/PI apoptosis detection kit (Beijing Biosea Biotechnology Co., Ltd, Beijing, China) according to manufacturer's recommendations. MiR-transfected cells were collected and suspended in $200 \mu \mathrm{l}$ of binding buffer containing $10 \mu \mathrm{l}$ Annexin V-FITC and $5 \mu \mathrm{l}$ of PI, then incubated at room temperature for $30 \mathrm{~min}$ in the dark. Apoptotic cells were measured with flow cytometer (Beckman Coulter, Miami, FL, USA) (13).

Dual-Luciferase activity assay. The 3'-untranslated regions (3'-UTR) of Twist1 was amplified by PCR and placed into the pMiR-report vector (Ambion, Carlsbad, CA, USA). MG63 cells were cotransfected with $0.5 \mu \mathrm{g}$ of the recombin Twist1 report vector and miR-300 mimics using Lipofectamine 3000 (Invitrogen Life Technologies). The recombinant repot vector carrying the Twist1 mutation sequence or the empty report vector were also cotransfected with miR-300 into MG63 cells and activted as controls, respectively. Forty eight hours after transfection, cells were collected and Dual-Luciferase activities were measured using the Dual-Luciferase reporter assay kit (Promega Corp., Madison, WI, USA) following to the manufacture's information (14).

RNA extraction and quantitative polymerase chain reaction $(q P C R)$. Total RNA was extracted with Trizol (Invitrogen Life Technologies) and reversely transcribed by MultiScribe RT kit (Applied Biosystems Life Technologies, Foster City, CA, USA) according to the manufacturer's instructions. All reverse transcriptase reactions, including no template controls and real-time minus controls, were run in a master cycler gradient (Eppendorf AG, Hamburg, Germany). For the qPCR analysis, FastStart Universal SYBR-Green Master (15) (Roche Diagnostics, Indianapolis, IN, USA) was used according to the manufacturer's instructions. The qPCR was performed in triplicate, including no template controls. MiR-300 and Twist1 expressions were respectively normalized to U6 and glyceraldehyde-3-phosphate dehydrogenase (GAPDH) expressions using $2^{-\triangle \Delta C T}$ method (16). All primers for qPCR were synthesized by GenePharma Co. The data were analyzed with Real-Time StatMiner (Integromics, Granada, Spain).

Western blot analysis. The protein expression changes in miR-300 transfected cells were detected by western blot analysis. The simples were extracted by lysis buffer (Beyotime Institute of Biotechnology, Shanghai, China) supplemented with protease inhibitors (Roche Diagnostics Ltd., Guangzhou, China). Proteins were quantified using the $\mathrm{BCA}^{\mathrm{TM}}$ Protein Assay kit (Pierce, Appleton, WI, USA). Equal amounts of 
protein were separated by $10 \%$ sodium dodecyl sulfate polyacrylamide gel electrophoresis (SDS-PAGE) and transferred to polyvinylidene fluoride (PVDF) membranes. Membranes were incubated with specific primary antibodies (all 1:1,000): Twist1 (sc15393), inhibitor of NF- $\kappa \mathrm{B}$ alpha (I $\mathrm{B} \alpha, \mathrm{sc} 847$ ), phosphorylated $\mathrm{I} \kappa \mathrm{B} \alpha(\mathrm{p}-\mathrm{I} \kappa \mathrm{B} \alpha, \mathrm{sc} 101713)$, p65 (sc109), phosphorylated p65 (p-p65, sc101749), B cell lymphoma/lewkmia-3 (Bcl-3, sc185) (Santa Cruz Biotechnology, Inc., Dallas, TX, USA) or GAPDH (ab8245; Abcam, Cambridge, MA, USA), overnight at $4^{\circ} \mathrm{C}$. Then the membranes were incubated with horseradish peroxidase-conjugated secondary antibodies (1:5,000, sc2004; Santa Cruz Biotechnology, Inc.) for $1 \mathrm{~h}$ at room temperature. Protein bands were developed by enhanced chemiluminescence and were analyzed by Image Lab ${ }^{\mathrm{TM}}$ Software (Bio-Rad Laboratories Co., Shanghai, China).

Statistical analysis. Data were presented as mean \pm standard deviation (SD), which were representative of at least three independent experiments and analyzed using GraphPad Prism 5 software (GraphPad Software, Inc., La Jolla, CA, USA). The P-values were calculated using the two-tailed Student's t-test to evaluate the significance of differences between two groups, and one-way analysis of variance for multiple groups (17). $\mathrm{P}<0.05$ was considered to indicate a statistically significant difference.

\section{Results}

Overexpression of miR-300 inhibited cell viability and migration while increased apoptosis of MG63 cells. In the present study, the expression levels of miR-300 in OS cells were measured by qPCR. It was verified that miR-300 was effectively overexpressed or suppressed $(\mathrm{P}<0.001)$ in MG63 cells after transfection (Fig. 1).

MTT results (Fig. 2A) showed that after transfection with miR-300 mimic, the MG63 cells viability was inhibited, and it was much lower than in the control group in 2-4 days $(\mathrm{P}<0.001)$. However, suppression of miR-300 displayed the opposite results at the same time points $(\mathrm{P}<0.01)$. The results from migration assay (Fig. 2B) showed that, cell migration was significantly decreased by miR-300 overexpression $(\mathrm{P}<0.001)$, while increased by miR-300 suppression $(\mathrm{P}<0.001)$. Besides, results in Fig. 2C and D showed that miR-300 overexpression significantly enhanced the relative rate of apoptosis $(\mathrm{P}<0.001)$, while miR-300 suppression group showed the opposite result $(\mathrm{P}<0.05)$. Therefore, miR-300 might affect cell viability and migration, and might be a key regulator for apoptosis in MG63 cells.

MiR-300 directly targeted Twistl in the MG63 cells. To test the relationship between miR-300 and Twist1, we cloned the Twist1 3'-UTR region fragment into the luciferase reporter system and co-transfected with miR-300 mimic into MG63 cell lines. We found that only the Twist1 reporter group displayed obvious inhibition $(\mathrm{P}<0.01)$ when co-transfected with miR-300 mimic (Fig. 3A). This result suggested that miR-300 directly targeted Twist1 3'-UTR in MG63 cells.

To further demonstrate how miR-300 affected Twist1, we overexpressed or suppressed miR-300 in MG63 cells, then assessed the protein expression levels of Twist1. We found

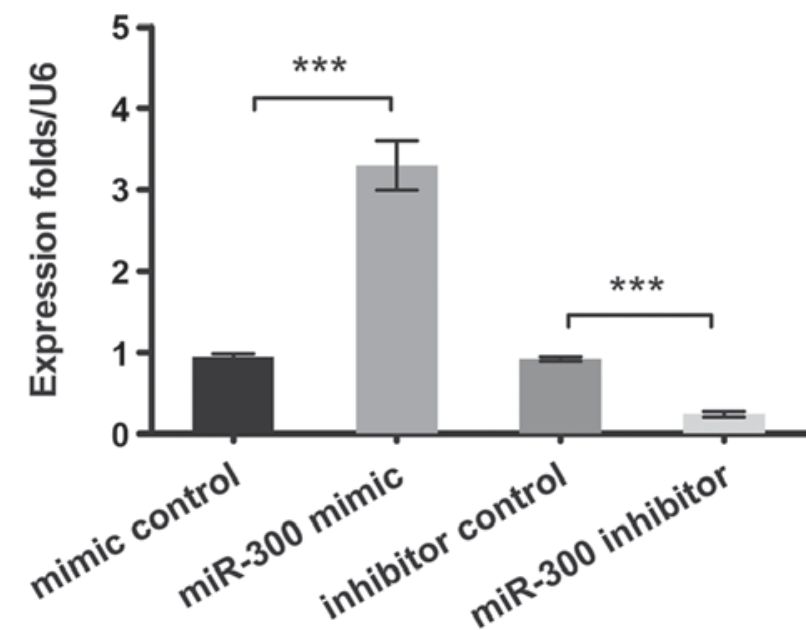

Figure 1. Efficiency of transfection on miR-300 expression in MG63 cells The mRNA level expression of miR-300 in miR-300 mimic or inhibitor infected MG63 cells were measured by qPCR. U6 acted as an internal control. MiR-300, microRNA-300; qPCR, quantitative polymerase chain reaction; ${ }^{* * *} \mathrm{P}<0.001$.

that overexpression of miR-300 caused the Twist1 protein level decrement, while the miR-300 inhibitor enhanced the Twist1 expression in MG63 cells ( $\mathrm{P}<0.001$; Fig. 3B). The data demonstrated that Twist1 was negatively regulated by miR-300 in MG63 cells.

MiR-300 downregulated expression of $N F-\kappa B$ regulated proteins in MG63 cell. To further explore the underlying molecular mechanisms of miR-300 in MG63 cells, we detected the expression of selected $\mathrm{NF}-\kappa \mathrm{B}$ pathway-related proteins (IkB $\alpha$, p65 and Bcl-3). MG63 cells were transfected with miR-300 mimic, exogenous expressed Twist1, or both of them, respectively. As shown in Fig. 4A and B, the expression of $\mathrm{p}-\mathrm{IkB} \alpha, \mathrm{p}-\mathrm{p} 65$ and Bcl-3 were significantly decreased in miR-300 mimic treated group $(\mathrm{P}<0.05)$. However, Twist1 significantly upregulated the expression of $\mathrm{p}-\mathrm{IkB} \alpha, \mathrm{p}-\mathrm{p} 65$ and $\mathrm{Bcl}-3$, and reversed the inhibitive effects of miR-300 on these proteins expressions $(\mathrm{P}<0.001)$. Therefore, we inferred miRNA-300 suppressed activation of the NF- $\kappa \mathrm{B}$ signaling pathway by inhibiting Twist1.

\section{Discussion}

In cancer, miRNAs serve as proto-oncogenes or tumor suppressor genes, depending on their regulatory effect (18). Nowadays, plenty of miRNAs have been found as oncogenes or anti-oncogenes in OS (19-21). However, little literatures were reported the potential role of miR-300 in the pathogenesis of OS. The present study aimed to investigate the role of miR-300 in OS cells, and explored the possible mechanisms. We found that miR-300 level was negatively correlated with cell viability and migration in MG63 cells, and was positively correlated with cell apoptosis. Twistl was a direct target gene of miR-300, and in vitro investigations revealed that Twist1 was negatively regulated by miR-300. More importantly, $N F-\kappa B$ pathway was implicated in the role of miR-300 in OS cells. 

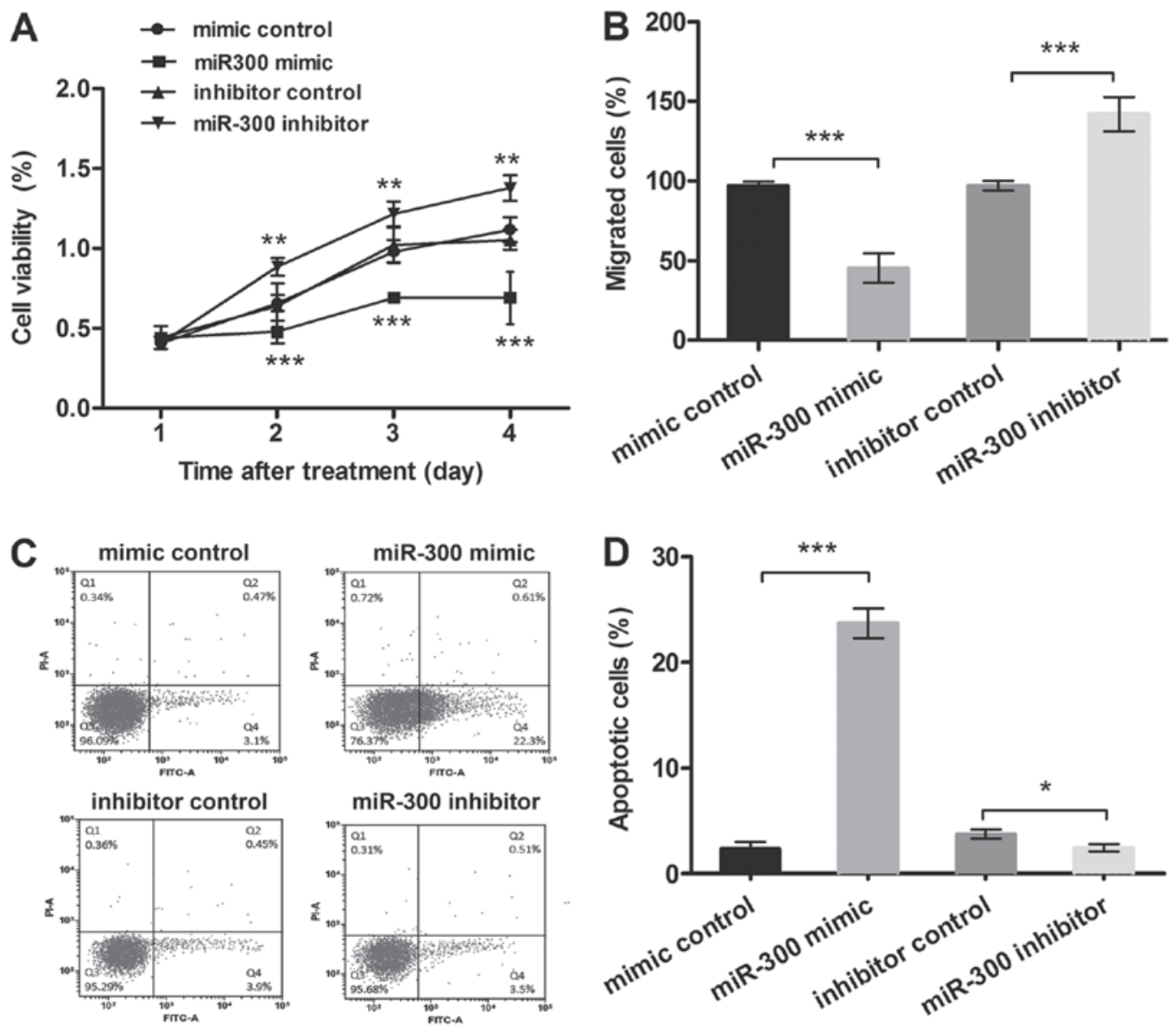

Figure 2. Overexpression of miR-300 suppressed cell viability and migration while enhanced apoptosis of MG63 cells. MiR-300 mimic, miR-300 inhibitor or scramble control was transfected into MG63 cells respectively. (A) The transfected cells were collected and cultured for 1-4 days, cell viability was determined by MTT assay. (B) The migration of transfected cells were measured by Transwell assay. (C and D) The apoptotic cells rate was detected by flow cytometry. MiR-300, microRNA-300; MTT, 3-(4,5-dimethyl-2-thiazolyl)-2,5-diphenyltetrazolium bromide; ${ }^{*} \mathrm{P}<0.05 ;{ }^{* * *} \mathrm{P}<0.01 ;{ }^{* * * *} \mathrm{P}<0.001$.
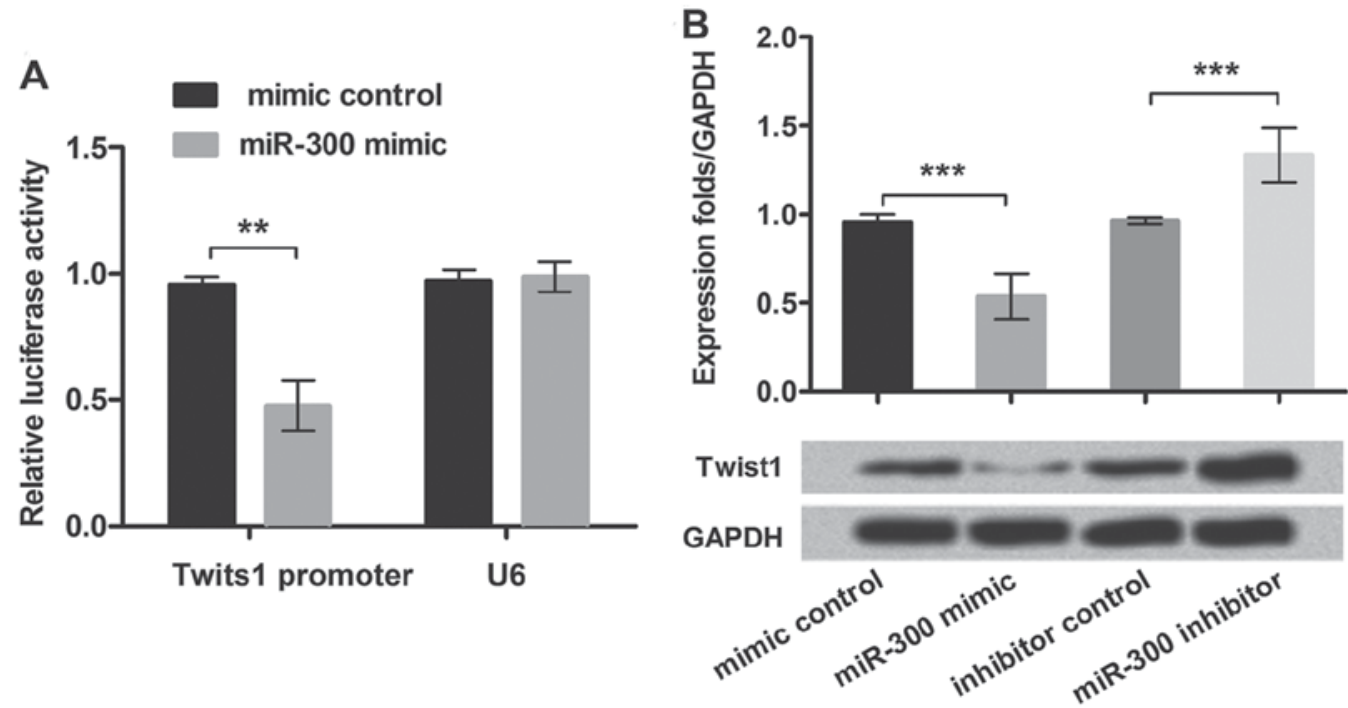

Figure 3. Twist1 was a direct target of miR-300. (A) Dual-Luciferase reporter assay was performed to confirm miR-300 targeted the 3'-UTR of Twist1. (B) The protein level of Twist lexpression in miR-300 overexpressed cells or miR-300 suppressed cells were detected by western blot. GAPDH acted as an internal control. MiR-300, microRNA-300; 3'-UTR, 3'-untranslated regions, ${ }^{* *} \mathrm{P}<0.01,{ }^{* * *} \mathrm{P}<0.001$.

Previous studies have demonstrated the versatile roles of miRNAs in cancer. MiRNA abnormal expression were found in a variety of tumors, and dysregulation of miRNAs has been proposed to be a rising feature in cancer $(22,23)$. Deregulated expression of miR-300 has been studied in a lot of cancers, such as urothelial carcinoma of the bladder (BUC) (24) and 
A
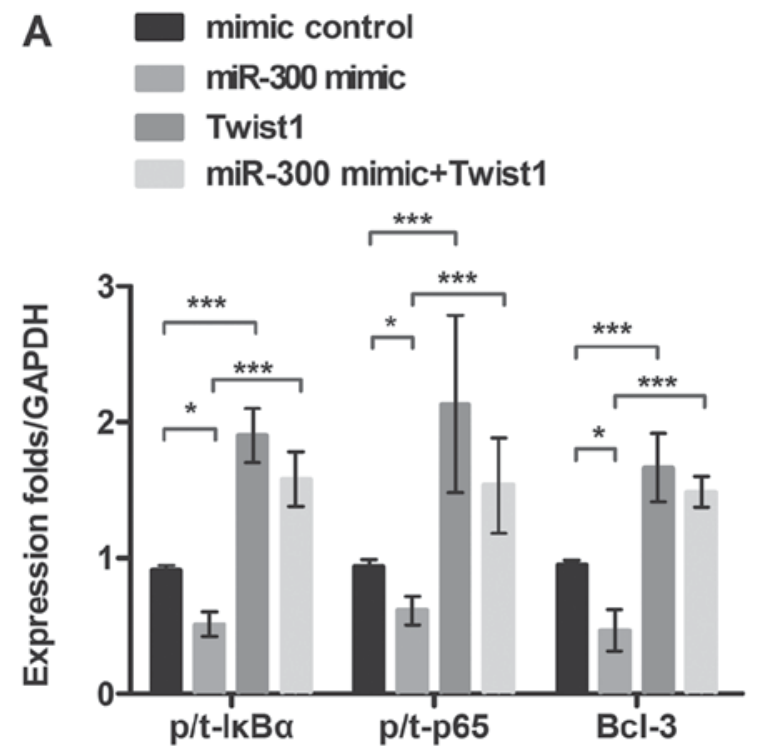

B

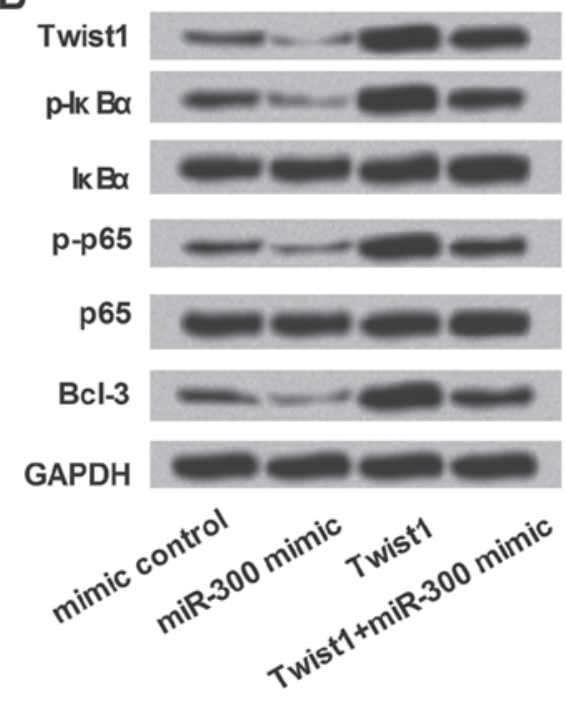

Figure 4. MiR-300 downregulates expression of NF- $\mathrm{B}$ regulated proteins in MG63 cells. MG63 cells were transfected with miR-300 mimic, exogenous

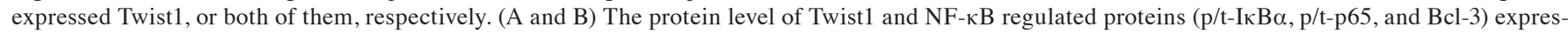
sion in miR-300 treated MG63 cells were detected by western blot. GAPDH acted as an internal control. MiR-300, microRNA-300; NF- $\mathrm{B}$, Nuclear

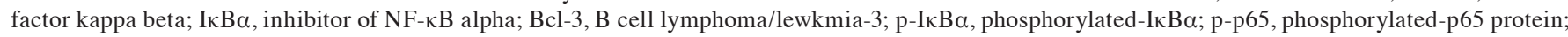
${ }^{* * *} \mathrm{P}<0.01,{ }^{* * *} \mathrm{P}<0.001$.

colorectal cancer (25). It also has been demonstrated that overexpression of miR-300 inhibited cell proliferation, cell cycle and invasion in glioblastoma cell line (9). In terms of OS, miR-300 have been reported to be associated with progression of OS and might act as predictor biomarker in the prognosis of OS (26). A previous study in MG63 cell line indicated the pro-proliferation and pro-invasion roles of miR-300 (27). In the present study, the discrepant functions of miR-300 were found in the same OS cell line. Our data indicated that overexpression of miR-300 notably suppressed cell viability and migration while enhanced apoptosis in MG63 cells. Actually, many different types of miRNAs were abnormally expressed and affected OS cells proliferation and apoptosis in different degree. For instance, miR-125b has been reported as oncogenic as well as anti-oncogenic, depending on the tumor type, and both miR-300 and miR-125b were probably involved in pathogenesis of OS (28). The disparity of miR-300 effect on MG63 cells might be caused by the complex function of miR-300, also particular environment tested would lead to the alteration of other miRNAs expressions which was related with miR-300 expression, and it might be another reason of triggering the contradictory results regarding miR-300 in the MG63 cells. Therefore, further studies on the exact role of miR-300 are urgently needed.

The Twist1 transcription factor was known to promote tumor metastasis, and induce epithelial-mesenchymal transition (EMT) which is the important evidence of degree for malignancy increased (11). Twist1 was also related to the formation of cancer halting terminal differentiation, inhibiting apoptosis, and interfering with the p53 tumor-suppressor pathway (29). Besides, Twist1 has been confirmed as a target gene of miR-106b, miR-720 and miR-33b, which are involved in cancer cell modulation (30-32). However, our data suggested that Twist1 might also be a direct target of miR-300.
Additionally, we found that Twist1 was negatively regulated by miR-300 in MG63 cells.

Previous studies reported that Twist1 could decrease OS cell survival against cisplatin by inhibiting multiple signaling pathways, such as EMT, phosphatidylinositol-3 kinase/protein kinase B (PI3K/AKT), NF- $\kappa$ B and signal transducer and activator of transcription (STAT3) pathways, all of them formed a complex and multichannel system (33-35). In addition, NF- $\kappa \mathrm{B}$ is a major signaling pathway nearly ubiquitous responsible for mediating DNA transcription and cell function $(36,37)$. It has been detected that Twist1 regulated EMT via the NF- $\kappa$ B in many cell types $(38,39)$. Activation of $\mathrm{NF}-\kappa \mathrm{B}$ also plays a major role in inhibiting apoptosis by causing up-regulation of key anti-apoptotic proteins such as Bcl-3, B cell lymphoma/lewkmia-xl (Bcl-xl), X-linked inhibitor of apoptosis protein (XIAP) and survivin $(40,41)$. To further explore the deeply associated mechanism of miR-300 in MG63 cells, expression of regulated proteins in $\mathrm{NF}-\kappa \mathrm{B}$ pathway were measured. We found that the expression level of p-I $\kappa \mathrm{B} \alpha, \mathrm{p}-\mathrm{p} 65$ and $\mathrm{Bcl}-3$ were decreased significantly in miR-300 mimic transfected cells, whereas Twist1 reversed these decreases. Among these proteins, p65 is one part of the NF- $\kappa \mathrm{B}$ dimer, I $\kappa \mathrm{B} \alpha$ acts as inhibitory factor of $\mathrm{NF}-\kappa \mathrm{B}$ and $\mathrm{Bcl}-3$ contributes to the regulation of transcriptional activation of $\mathrm{NF}-\kappa \mathrm{B}$ target genes. Taken together, these data clearly indicated that miRNA-300 could suppress activation of the NF- $\kappa \mathrm{B}$ signaling pathway by inhibiting Twist1.

Our results demonstrated that overexpression miR-300 suppressed cell viability and migration, while promoted apoptosis in MG63 cells. These processes might be via downregulation of Twist1, and ultimately resulting in inactivation of the NF- $\mathrm{B}$ pathway. MiRNA-300 might be a potential target for the specific gene treatment of OS. Based on the results as outlined above, further investigation is warranted to investigate the mechanisms of miR-300's effect on OS in more types 
of signal pathways and OS cell lines, and more in vivo studies are also needed in the future.

\section{References}

1. Picci P: Osteosarcoma (osteogenic sarcoma). Orphanet J Rare Dis 2: 6, 2007.

2. Peng L: Progress in the treatment of osteosarcoma. Int $J$ Orthop 29: 91-93, 2008.

3. Qiu Z and Liao Q. Progress of osteosarcoma therapy. Zhongguo Xiu Fu Chong Jian Wai Ke Za Zhi 24: 1469-1475, 2010 (In Chinese).

4. Jones-Rhoades MW and Bartel DP: Computational identification of plant micrornas and their targets, including a stress-induced miRNA. Mol Cell 14: 787-799, 2004.

5. Ambros V: The functions of animal microRNAs. Nature 431: 350-355, 2004

6. Zalfa F, Giorgi M, Primerano B, Moro A, Di Penta A, Reis S, Oostra $\mathrm{B}$ and Bagni $\mathrm{C}$ : The fragile $\mathrm{X}$ syndrome protein FMRP associates with $\mathrm{BC} 1 \mathrm{RNA}$ and Regulates the translation of specific mRNAat synapses. Cell 112: 317-327, 2003.

7. Iorio MV and Croce CM: MicroRNAs in cancer: Small molecules with a huge impact. J Clin Oncol 27: 5848-5856, 2009.

8. Liu X, Liu L, Xu Q, Wu P, Zuo X and Ji A. MicroRNA as a novel drug target for cancer therapy. Expert Opin Biol Ther 12: 573-580, 2012.

9. Zhou F, Li Y, Hao Z, Liu X, Chen L, Cao Y, Liang Z, Yuan F, Liu J, Wang J, et al: MicroRNA-300 inhibited glioblastoma progression through ROCK1. Oncotarget 7: 36529-36538, 2016.

10. Nairismägi ML, Füchtbauer A, Labouriau R, Bramsen JB and Füchtbauer EM: The proto-oncogene TWIST1 is regulated by microRNAs. PLos One 8: e66070, 2013.

11. Sánchez-Tilló E, Liu Y, de Barrios O, Siles L, Fanlo L, Cuatrecasas M, Darling DS, Dean DC, Castells A and Postigo A: EMT-activating transcription factors in cancer: Beyond EMT and tumor invasiveness. Cell Mol Life Sci 69: 3429-3456, 2012.

12. Cho WH, Lee HJ, Choi YJ, Oh JH, Kim HS and Cho HS Capsaicin induces apoptosis in MG63 human osteosarcoma cells via the caspase cascade and the antioxidant enzyme system. Mol Med Rep 8: 1655-1662, 2013.

13. Zhang N, Su Y and Xu L: Targeting PKCE by miR-143 regulates cell apoptosis in lung cancer. FEBS Lett 587: 3661-3667, 2013.

14. Shi W, Bruce J, Lee M, Yue S, Rowe M, Pintilie M, Kogo R, Bissey PA, Fyles A, Yip KW and Liu FF: MiR-449a promotes breast cancer progression by targeting CRIP2. Oncotarget 7: 18906-18918, 2016.

15. Rojas RE, Balaji KN, Subramanian A and Boom WH: Regulation of human CD4(+) alphabeta T-cell-receptor-positive (TCR $(+))$ and gammadelta TCR(+) T-cell responses to Mycobacterium tuberculosis by interleukin-10 and transforming growth factor beta. Infect Immun 67: 6461-6472, 1999.

16. Livak KJ and Schmittgen TD: Analysis of relative gene expression data using real-time quantitative PCR and the 2(-Delta Delta C(T)) Method. Methods 25: 402-408, 2001.

17. Shin SS, Keshavjee S, Gelmanova IY, Atwood S, Franke MF, Mishustin SP, Strelis AK, Andreev YG, Pasechnikov AD, Barnashov A, et al: Development of extensively drug-resistant tuberculosis during multidrug-resistant tuberculosis treatment. Am J Respir Crit Care Med 182: 426-432, 2010.

18. Ambros V: microRNAs: Tiny regulators with great potential. Cell 107: 823-826, 2001.

19. Wang GC, He QY, Tong DK, Wang CF, Liu K, Ding C, Ji F and Zhang H: MiR-367 negatively regulates apoptosis induced by adriamycin in osteosarcoma cells by targeting KLF4. J Bone Oncol 5: 51-56, 2016.

20. Lin BC, Huang D, Yu CQ, Mou Y, Liu YH, Zhang DW and Shi FJ: MicroRNA-184 modulates doxorubicin resistance in osteosarcoma cells by targeting BCL2L1. Med Sci Monit 22: 1761-1765, 2016.

21. Geng S, Gu L, Ju F, Zhang H, Wang Y, Tang H, Bi Z and Yang C: MicroRNA-224 promotes the sensitivity of osteosarcoma cells to cisplatin by targeting Rac1. J Cell Mol Med 20: 1611-1619, 2016.
22. Lu J, Getz G, Miska EA, Alvarez-Saavedra E, Lamb J, Peck D, Sweet-Cordero A, Ebert BL, Mak RH, Ferrando AA, et al: MicroRNA expression profiles classify human cancers. Nature 435: 834-838, 2005.

23. Calin GA, Sevignani C, Dumitru CD, Hyslop T, Noch E, Yendamuri S, Shimizu M, Rattan S, Bullrich F, Negrini M and Croce CM: Human microRNA genes are frequently located at fragile sites and genomic regions involved in cancers. Proc Natl Acad Sci USA 101: 2999-3004, 2004.

24. Xu F, Gao J, Zhang Z, Ge J, Wei Z and Cheng W: Expression of miRNA-300 in urothelial carcinoma of the bladder. J Medical Res, 2012.

25. Lin W: A preliminary study of miRNA-300 regulation in invasion and proliferation of colorectal cancer (unpublished PhD thesis). Third Military Medical University, 2015 (In Chinese).

26. Karbasy SH, Taheriazam A, Mirghasemi A, Sedaghati F, Shakeri M, Yahaghi E and Bahador R: RETRACTED ARTICLE: Upregulation of miR-300 and downregulation of miR-125b act as potential predictor biomarkers in progression, metastasis, and poor prognosis of osteosarcoma. Tumor Biol, 2015 (Epub ahead of print).

27. Xue Z, Zhao J, Niu L, An G, Guo Y and Ni L: Up-regulation of MiR-300 promotes proliferation and invasion of osteosarcoma by targeting BRD7. PLoS One 10: e0127682, 2015.

28. Banzhaf-Strathmann J and Edbauer D: Good guy or bad guy: The opposing roles of microRNA $125 \mathrm{~b}$ in cancer. Cell Commun Signal 12: 30, 2014.

29. Maestro R, Dei Tos AP, Hamamori Y, Krasnokutsky S, Sartorelli V, Kedes L, Doglioni C, Beach DH and Hannon GJ: Twist is a potential oncogene that inhibits apoptosis. Genes Dev 13: 2207-2217, 1999.

30. Li LZ, Zhang CZ, Liu LL, Yi C, Lu SX, Zhou X, Zhang ZJ, Peng YH, Yang YZ and Yun JP: miR-720 inhibits tumor invasion and migration in breast cancer by targeting TWIST1. Carcinogenesis 35: 469-478, 2014.

31. Nairismägi ML, Füchtbauer A, Labouriau R, Bramsen JB and Füchtbauer EM: The protooncogene TWIST1 is regulated by microRNAs. PLoS One 8: e66070, 2013.

32. Dong P, Kaneuchi M, Watari H, Sudo S and Sakuragi N: MicroRNA-106b modulates epithelial-mesenchymal transition by targeting TWIST1 in invasive endometrial cancer cell lines. Mol Carcinog 53: 349-359, 2014.

33. Zhou Y, Zang X, Huang Z and Zhang C: TWIST interacts with endothelin-1/endothelin A receptor signaling in osteosarcoma cell survival against cisplatin. Oncol Lett 5: 857-861, 2013.

34. Wu J, Liao Q, He H, Da Z and Ke Y: TWIST interacts with $\beta$-catenin signaling on osteosarcoma cell survival against cisplatin. Mol Carcinog 53: 440-446, 2014.

35. Xu G, Shen J, Yu A, Wang H, Man TK and Lau CC: Abstract 3402: Knockdown of TWIST1 increases chemosensitivity of osteosarcoma cells. Cancer Res 70: 3402, 2010.

36. Wullaert A, Verstrepen L, Van Huffel S, Adib-Conquy M, Cornelis S, Kreike M, Haegman M, El Bakkouri K, Sanders M, Verhelst K, et al: LIND/ABIN-3 is a novel lipopolysaccharide-inducible inhibitor of NF-kappaB activation. J Biol Chem 282: 81-90, 2007.

37. Zhao Y, Li Z, Wang W, Zhang H, Chen J, Su P, Liu L and Li W: Naringin protects against cartilage destruction in osteoarthritis through repression of NF- $\kappa$ B signaling pathway. Inflammation 39: 385-392, 2016.

38. Horikawa T, Yang J, Kondo S, Yoshizaki T, Joab I, Furukawa M and Pagano JS: Twist and epithelial-mesenchymal transition are induced by the EBV oncoprotein latent membrane protein 1 and are associated with metastatic nasopharyngeal carcinoma. Cancer Res 67: 1970-1983, 2007.

39. Lv N, Shan Z, Gao Y, Guan H, Fan C, Wang H and Teng W: Twistl regulates the epithelial-mesenchymal transition via the NF- $\kappa$ B pathway in papillary thyroid carcinoma. Endocrine 51: 469-477, 2016.

40. Sethi G, Ahn KS and Aggarwal BB: Targeting nuclear factor-kappa $\mathrm{B}$ activation pathway by thymoquinone: Role in suppression of antiapoptotic gene products and enhancement of apoptosis. Mol Cancer Res 6: 1059-1070, 2008.

41. Brandwood CP, Hoyland JA, Hillarby MC, Berry JL, Davies M, Selby PL and Mee AP: Apoptotic gene expression in Paget's disease: A possible role for Bcl-2. J Pathol 201: 504-512, 2003. 